University has embarked on a building programme which must be completed in the next five or six years and will cost, in all, about $£ 6,000,000$. Most of this money will almost certainly come from the Government which, on the advice of the University Grants Committee, has selected Leeds as one of four univer. sities outside London for 'major developments' in the field of scientific and technological education. The Government has made it clear, however, that it has chosen to help the University of Leeds largely because it believes that Leeds can continue to count on help from other sources; for at least $\$ 600,000$ of the total needs the University has to look to industry and commerce and to private benefactors. Already $£ 200,000$ of this sum has been assured by gifts and promises. The Vice-Chancellor has now issued an appeal to many firms to help the University in its development work. There is little doubt that the appeal will be successful.

\section{Rotherham College of Technology}

To mark the twenty-fifth anniversary of the opening of the main building of the Rotherham College of Technology, a Jubilee Foundation Lecture was delivered on November 6 by Mr. R. F. Jackson, operations group leader in the Reactor Division of the Atomic Energy Research Establishment at Harwell, on "Research Reactors in the Nuclear Power Programme". During the quarter of a century since its foundation the Rotherham College of Technology has made a valuable contribution to industry in the Rotherham and Sheffield area. In carrying out extensive pioneer work in technical education it has established a high reputation, both locally and nationally; and during the past four years it has become the regional centre for south Yorkshire for powder metallurgy, furnace brickwork and for sandwich courses in mechanical and electrical engineering.

\section{Clinica Chimica Acta}

THE newer biochemical techniques, in particular improved methods of separation, such as chromatography and electrophoresis, and the use of isotopic tracers, are opening endless avenues for exploration by those engaged in medical research. As a result, papers on $e^{\mathrm{l} i n i c a l}$ biochemistry are appearing in ever-increasing numbers. 'These papers are now spread among a wide variety of journals and are often regarded as too clinical by the pure biochemist and as too biochemical by the pure clinician. As a result, in several countries journals have been, or are being, initiated to cater for clinical biochemistry as a scientific discipline in its own right. Messrs. Elsevier have given substance to hopes expressed at the first International Congress on Clinical Chemistry, held in Amsterdam in September 1954, that there should be started an international journal in this field. The new journal is a commercial veriture, not attached to any scientific society, and the publishers have been able to assemble an editorial board and an advisory board impressive in their high standing, and carrying assurance of a sound editorial policy (Elsevier Publishing Co., Ltd., Amsterdam, London, Houston, New Yorlk. Six issues per year, of approximately 100 pages each. $£ 410 s$. per volume of 6 issues). The international flavour is shown both by the composition of the editorial board (the fourteen members of which represent eleven countries) and by the authorship of the thirty-one papers in the first three issues, contributed from ten countries. A very desirable, but probably rather expensive, feature is that summaries of all papers are given in four languages-English, French, German and Russian. This should encourage one of the subsidiary hopes of its founders, namely, that the journal will promote some degree of standardization in biochemical procedures applied to medicine, and thereby facilitate mutual interpretation of results. The format and standard of production are of the high quality which one has learnt to associate with Elsevier publications. The price, as seems almost inevitable nowadays, makes the journal more likely to be taken by libraries than by individuals. If a high editorial standard is maintained, this journal is likely to come to be considered of prime importance in all institutions concerned with clinical biochemistry.

\section{Midwest Research Institute, Kansas City : Annual Report \\ THe annual report of the Midwest Research} Institute, Kansas City, Mo. (pp. 16; 1956), presented by the president, Dr. C. N. Kimball, to the 'Trustees at their eleventh annual meeting on May 14, records a 20 per cent increase in the amount of contract research, which amounted to $2,170,000$ dollars in value on 503 different projects for 208 sponsors. Of the Institute's full-time staff, 175 are professional research workers and more than half the work was based on ideas originating with the Institute's own staff. Among projects noted by Dr. Kimball are the work on air pollution in Los Angeles, now in its third year, involving the determination of the effect of materials emanating from automobile exhausts; the development of industrial products, such as polymers from non-edible tallows and greases; and the design of an electromechanical device which, in a relatively small space, simulates operating conditions in an oil-well with respect to the performance of its components. In the field of automation, methods and equipment have been developed for checking practical horse-power motors to meet the requirements of the National Electrical Manufacturers Association, and among the projects on which the eleven people engaged in marketing research have been occupied is an analysis of factors affecting the market potential for anhydrous ammonia as fertilizer. Those engaged in operations research have made a study of the possibility of setting up a mathematical model which would govern inventory policy. Work has been done on the addition of chemicals to food prior to irradiation, and a group of people with extensive experience in the field of nuclear energy is being formed. Projects bearing directly on public health or wealth included broad studies of the basic economy of the Great Plains Area; methods of transmitting to the mind of the blind person information about objects beyond his reach; and the development of an artificial lung and heart to permit operations on the human heart itself. Dr. Kimball believes that in future the production of new technology will become a competitive business activity, and he also stresses the importance of new materials and techniques.

\section{Pacific Science Board: Report for 1954}

THe eighth annual report of the Pacific Science Board for 1954 (pp. 61. Washington, D.C. : National Academy of Sciences-National Research Council, 1955) summarizes the progress made in studying the environmental factors affecting life on coral atolls, which has been the chief activity of the programme 